\title{
Stigma, prejudice and discrimination in global public health
}

\author{
Estigma, preconceito e discriminação \\ na saúde pública global
}

\begin{abstract}
1 Mailman School of Public Health, Columbia University, New York, USA.

Correspondence R. Parker

Mailman School of Public Health, Columbia University. 722 W. 168th St., 5th Floor, New York, NY - 10032, USA. rgp11@columbia.edu
\end{abstract}

\begin{abstract}
This article reviews the development of international research on the relationship between discrimination and health. It provides an overview of theoretical and empirical work on stigma and prejudice and their impact on discrimination and health. It argues that the literature on these issues has drawn primarily from social psychology and has focused on the impact of attitudes associated with stigma and prejudice on discriminatory practices and consequently health outcomes. It also identifies a growing trend in recent research towards a reconceptualization of stigma, prejudice and discrimination from the perspective of social inequality and structural violence, highlighting relations of power and exclusion that reinforce vulnerability within a complex social and political process. It concludes by briefly examining the ways in which this reconceptualization of discriminatory practices has generated a growing interest in the linkages between health and human rights and renewed interest in health and social justice; two major trends in the field of global public health.
\end{abstract}

Social Stigma; Prejudice; Social Inequality
Richard Parker 1

\section{Introduction}

Over the past two decades, there has been growing interest in the relationship between discrimination and health. Although an exhaustive global review of literature on this subject is beyond the scope of this brief article, it is important to highlight some of the most important lines of theorization and empirical research that characterize this area and identify some of the key findings that might guide practical and programmatic responses to human suffering and health challenges caused by discrimination.

\section{Stigma, prejudice and discrimination}

Stigma, prejudice, and discrimination have been an important focus of research attention for a number of decades. In 1963, Goffman's pioneering book, Stigma: Notes on the Management of Spoiled Identity, initiated a debate about the nature of stigma and discrimination that has grown steadily over the last 50 years 1 . The present work examined a wide variety of topics, many of which were first examined by Goffman and subsequently studied from a variety of disciplinary perspectives: physical disfigurement and disabilities, mental illness, homelessness, homosexuality and gender nonconformity, juvenile delinquency, and other issues associated with non-normal 
and non-normative experiences or behavior 2 . Study topics vary and disciplinary approaches to stigma include anthropology, psychology, sociology, education, public health and social work. However, the majority of research carried out to date in this area has focused on stigma and its relation to health conditions (especially mental illness and HIV infection) and has drawn principally from social psychology. The emergence of the HIV/AIDS epidemic in the 1980s can be considered a watershed event for stigma research and work on HIV/AIDS-related stigma and discrimination has "boomed" over the course of the past three decades.

The history of research on prejudice and discrimination is similar to that of stigma. Although research on prejudice - linked to Allport's publication, the Nature of Prejudice 3 in 1954 - started slightly earlier, over the latter part of the $20^{\text {th }}$ century the two areas evolved along parallel but distinctly separate tracks. During much of this time, the development of research on prejudice and discrimination was motivated by growing social concern with racism, especially in the USA. Thus, work in this area has largely focused on race and ethnicity and how racial and ethnic discrimination are driven by prejudice, whereas work on stigma was more closely associated with health conditions ${ }^{4}$. Although research on both prejudice and stigma has been influenced by various fields of social sciences, psychology and social psychology have played a particularly important role in the development of literature in this area 5. However, whatever the conceptual framework, the focus on the relation of prejudice and discrimination to health outcomes and what has been described particularly in the United States as health disparities, has only emerged over the course of the past 10 to 15 years 4 .

In recent years, the focus on both stigma and prejudice has led to a growing body of work on the health consequences of discrimination experienced as a result of these processes. The effects of stigma have been explored in relation to the following sections of the community: people living with or perceived to be at risk of HIV infection 6; people suffering from mental illness 7,8; and the homeless 9 . A large body of work has emerged, particularly in the United States, that has sought to measure the experience of discrimination 10,11. In countries such as the Unites States and South Africa, that have experienced a long history of intense racial discrimination, research has been carried out with the aim of understanding the differential experience of "acute" as opposed to "chronic" racial and non-racial discrimination, and their impacts in relation to a range of stressors and psychological factors (such as social desirability, self-esteem and personal mastery) 12,13 . Both stigma and prejudice-related discrimination has been examined in relation to what Meyer and colleagues describe as "minority stress" 14 . While much of this work has examined the psychological and mental health impacts of stigma, prejudice and discrimination, there has also been a significant increase in work on violence related to these processes 15,16,17. This focus has directed critical attention to documenting the occurrence of discrimination and violation of rights, hate crimes, and the health consequences of discrimination. However, much still needs to be done to build on work in this area to be able to confront these negative consequences with more effective social and public health policies, programs, and interventions.

Due to the prevalence of a social psychology perspective in studies on this topic, stigma and prejudice have been conceptualized mainly as negative attitudes held by some in relation to the value of specific groups: racial and ethnic minorities, people that suffer from mental illness, people with HIV, and so on. Discrimination has been seen as a kind of behavioral response caused by these negative attitudes - or as a form of enacted stigma or enacted prejudice. A sharp distinction has thus been made between ideas, attitudes, or ideologies, and their behavioral consequences in discriminatory actions. This distinction between thought and action, in turn, has served as a point of departure for intervention. Many interventions have focused on the thoughts that are perceived to drive discriminatory practices, seeking to change negative attitudes by reducing levels of stigma or prejudice, thus reducing discriminatory actions.

\section{Rethinking stigma, prejudice and discrimination from the perspective of social inequality and structural violence}

In many ways, this was the basic conceptual architecture that Peter Aggleton and I questioned a little more than a decade ago in attempting to develop a new conceptual framework for analyzing stigma and its impact in relation to HIV/AIDS 18,19. In a series of articles published between 2000 and 2005, we argued that it would only be possible to advance in the fight against AIDSrelated stigma and discrimination by developing a new conceptual framework to guide actions and implement activities aimed at stimulating social mobilization and collective resistance in the face of discrimination. We argued that the time had come to move beyond Goffman's initial conceptual model of stigma as a kind of mark 
or negatively valued difference, and think about stigma as social process fundamentally linked to power and domination. (It should be noted that, in fairness to Goffman, who we probably used as something of a straw man in order to construct our argument, his original model actually placed greater emphasis on process than we gave him credit for). In our framework, we argued that stigma plays a key role in producing and reproducing relations of power and control: that the deployment of stigma causes some groups to be devalued and others to be valued in ways that are inherently discriminatory, and that the distinction between thought and action/theory and practice, should be reconceptualized as a more complex form of praxis. We argued that a clearer understanding of stigma from the perspective of social inequality is needed and that stigmatization and discrimination, whether in relation to HIV and AIDS or any other issue, can only be fully understood if society broadens its thinking about how certain individuals and groups come to be socially excluded and the forces that create and reinforce exclusion in different settings.

Aggleton and I certainly were not alone inn making this argument. A very similar argument was made at much the same time by Bruce Link and Jo Phelan, whose work focused on the relation of stigma to issues such as mental health and homelessness. In their influential review article in the Annual Review of Sociology 2, Link \& Phelan also placed emphasis on the relationship between stigma and power. In examining stigma and the HIV issue, we gave even greater emphasis to the emergence and evolution of stigma in specific contexts of culture and power. For this reason, stigma is not a free-floating social phenomenon; the historically determined nexus between cultural formulations and systems of power and domination is crucial. We argued that the period in which a stigma appears and the form it takes are always influenced by historical circumstances. Understanding this historical context and its consequences for affected individuals and communities can help us develop better approaches for combating this phenomenon and reducing its effects. This framework focuses on how stigma is used by individuals, communities and the state to produce and reproduce structures of social inequality. It also pushes us to examine the political economy of stigmatization and its links to social exclusion and how historically constructed forms of stigma are strategically deployed to produce and reproduce social inequalities.

While our work at the time focused exclusively on stigma, much of the analysis could clearly be applied just as well to the workings of prejudice and its relationship to discrimination, precisely because the model sought to develop a broader understanding of culture-power relations - the ways in which cultural meanings are deployed as part of a power system and how culture and power are mutually implicated and even dissassociable (rather than distinct spheres of theory and practice). Over the course of the past decade, this focus has become increasingly influential, and both stigma and prejudice have increasingly been conceptualized as fundamentally similar processes; or, as Jo Phelan and co-authors have argued: "one animal, not two" 5. These authors point out that research on stigma focuses on people with relatively "unusual" conditions such as facial disfigurement, mental illness, or HIV and AIDS. In contrast, research on prejudice tends to examine what might be described as more ordinary, but nonetheless powerful, forms of social inequality such as gender, age, race, or class. Both prejudice and stigma are quite similar social processes that can result in discrimination, involving categorization and labeling, stereotyping, and social rejection. But it appears that the historical circumstances underlying these processes in any one society may greatly vary. The research tradition of prejudice has grown out of concern with social processes driven by exploitation and domination, such as racism, while work on stigma has traditionally been more concerned with processes driven by the enforcement of norms or with disease avoidance. Reflecting on how these processes operate, Phelan and her colleagues developed a typology of three functions of stigma and prejudice: (1) exploitation and domination; (2) enforcement of social norms; and (3) disease avoidance. Phelan and colleagues described these functions as keeping people down, keeping people in, and keeping people away 5 .

Recent attempts to understand stigma, prejudice, and discrimination in terms of the broader relationship between cultural processes, power structures, and possibilities of resistance push us toward a more social and political understanding of these processes. This framework focuses attention on the linkages between stigma, prejudice, and discrimination and the workings of social inequality and processes of social exclusion. It is therefore useful to think about these processes from the perspective of "structural violence”. Johan Galtung is sometimes credited with being the first key thinker to develop the concept of structural violence 20. Galtung's conceptualization of structural violence is applicable to a range of issues, and has been applied effectively to topics related to health and illness. The theory of structural violence is especially useful in seeking to understand how structures constrain 
agency in ways that place people in situations of increased vulnerability.

Galtung defined structural violence as an "avoidable impairment of fundamental human needs or, to put it in more general terms, the impairment of human life, which lowers the actual degree to which someone is able to meet their needs below that which would otherwise be possible" 21 (p. 106). The key word here is "avoidable": if a person died from tuberculosis in the $18^{\text {th }}$ century it would be hard to conceive of this as violence since it might have been unavoidable given the medical services available at the time. However, if a person dies from tuberculosis today, with all the medical services that are available, then this can be considered as violence according to Galtung's definition 20. In Galtung's analysis, structural violence is different from personal or direct violence precisely because it is indirect: "there may not be any person who directly harms another person in the structure. The violence is built into the structure and shows up as unequal power and consequently as unequal life chances" 20 (p. 171).

This understanding was developed further by Paul Farmer and other anthropologists working along similar lines 22,23. Farmer argues, for example, that structural violence is "not the result of accident or a force majeure; it is the direct or indirect consequence of human agency" 23 (p. 40). In his view, the unequal distribution of power in society is the root cause of structural violence, and that creates disproportionate life chances because of disease or poverty. This unequal distribution of power systematically disadvantages - and therefore discriminates against - those who hold little or no power in society.

Whereas Farmer's work on structural violence focused on the role of poverty in shaping vulnerability to disease, studies carried out over the course of the 1990s and 2000s in a body of work that is sometimes described as "critical medical anthropology" highlighted a broader range of structural factors with emphasis on; poverty and economic exclusion, racial and ethnic inequalities, gender power differentials, sexual oppression, and age-related inequalities (affecting in particular the young and the elderly); together with a number of other more diffuse structural forces such as migration and dislocation (due to a number of factors ranging from seasonal labor migration to armed conflict and forced migration) 24 .

The evolving body of work on structural factors that shape vulnerability has made it possible to rethink the nature of discrimination in relation to health. The structural violence perspective allows us to reconceptualize discrimination not merely as an outcome in terms of psychological attitudes of a stigma or prejudice, but as the product of fundamentally unequal social and economic structures, so refocusing attention on what Link \& Phelan have described as the "fundamental causes" of disease 25 . This shift in focus challenges us to change our way of thinking when it comes to taking action to respond to the impact of discrimination in relation to health.

\section{Health and human rights/health and social justice}

Finally, it is important to discuss what I see as two major ethical/political perspectives in contemporary public or collective health that offer a potential response to the human suffering caused by stigma, prejudice and discrimination: the relatively new focus on health and human rights and the more traditional health and social justice perspective. While there are a number of important differences between these two approaches, they have increasingly converged in recent years, and together constitute the most important framework for thinking on action aimed at confronting the challenge of discrimination and its effects on health.

The most recent of the two perspectives, the health and human rights approach, developed over the course of the 1990s and 2000s. Its emergence was partly driven by the HIV epidemic in the 1980s which led to the resurgence and consolidation of stigma and discrimination related to HIV/AIDS and in many ways provided the institutional and political space for the growth of the health and human rights movement (the term "movement" may be too strong here - "approach" might be more appropriate). By the end of the century, the linkages between health and human rights were being articulated in all levels of global public health through the actions of various organizations including grassroots activists, transnational health social movements, and virtually all the key development agencies that provide foreign aid directed at confronting global health challenges 26 .

While the health and human rights approach has greatly influenced discourse on public or collective health in the early-21st century at grassroots and official governmental and intergovernmental levels, the concerns raised by this movement have for the most part been articulated in parallel with a second major line of thought that it is especially important in the discussion of discrimination and health: the health and social justice perspective. This approach can be traced back to the earliest days of what is known as so- 
cial medicine, and to the founding figures of the sanitary reform movement. Over the course of the $20^{\text {th }}$ century, concerns with health and social justice were played out through the development of public health and sanitary reform movements in various countries around the world. However, this approach had to contend with a range of narrower, biomedical and technical approaches that have typically been promoted by more conservative social forces and governments 27 . At precisely the time the global HIV/AIDS epidemic emerged, a growing neoliberal trend associated with an intensification of globalization had begun to spread across the globe, was a major step back for the principles of social justice articulated only a decade earlier in the Alma Ata Declaration 27. Indeed, this context may have led many activists, researchers and policymakers to adopt the human rights approach rather than social justice as an ethical/political rallying cry in seeking to respond to the growing HIV/AIDS epidemic. Yet, as neoliberal policies and perspectives continued to shape global public health, the focus on the need to link public health with social justice underwent a resurgence. It is interesting to note that this process was motivated by the same concerns with the health consequences of social inequality and structural violence that have shaped much recent thinking on stigma, prejudice and discrimination.
During the 1990s, it could be said that the health and human rights and health and social justice approaches competed with each another for primacy, just as the narrower focus on the linkages between stigma, discrimination and health seemed in some ways at odds with the broader understanding of discrimination as a result of social exclusion. Many involved in the field of public health, particularly those whose work focused more directly on social inequalities, were deeply concerned with a certain neoliberal Western bias in the health and human rights approach associated with the inability of those who had led the articulation of the health and human rights perspective to fully engage with the material conditions that make poverty such a driver of ill health around the world. Yet, one of the most important developments in the past decade is the extent to which these two approaches have begun to engage and come together 28 . While there is still much thinking to be done on the conceptual and political linkages between these two approaches, recent research on stigma, prejudice and discrimination and their relationship to health is at the forefront of exploring the nature of these interrelationships and building bridges between social theory and public health practice. It is precisely for this reason that this area of work has become one of the most vibrant fields of contemporary global public health.

\section{Resumo}

O artigo analisa as relações entre discriminação e saúde com base em uma revisão sobre os trabalhos teóricos e empíricos acerca de estigma e preconceito, e seus impactos na discriminação e na saúde. Argumenta-se que as pesquisas sobre tais temas têm sido desenvolvidas pela psicologia e pela psicologia social, tendo como foco o modo como as atitudes associadas ao estima e ao preconceito impactam nas práticas de discriminação e, em decorrência, na saúde. Todavia, é também identificada em pesquisas recentes uma crescente tendência de reconceituar estigma, preconceito e discriminação em relação aos modelos mais amplos de desigualdade social e violência estrutural, que destacam as relações de poder e exclusão que estruturam a vulnerabilidade como parte de um complexo processo social e político. Conclui-se analisando brevemente como a reconceitualização das práticas de discriminação tem contribuído para novas abordagens sobre saúde e direitos humanos, e para renovação do interesse na saúde e na justiça social, identificadas como duas tendências de grande importância no campo da saúde pública.

Estigma Social; Preconceito; Iniquidade Social 


\section{References}

1. Goffman E. Stigma: notes on the management of spoiled identity. Englewood Cliffs: Prentice-Hall; 1963.

2. Link B, Phelan J. Conceptualizing stigma. Annu Rev Sociol 2001; 27:363-85.

3. Allport G. The nature of prejudice. 25th anniversary edition. Cambridge: Perseus Books; 1979.

4. Stuber J, Meyer I, Link B. Stigma, prejudice, discrimination and health. Soc Sci Med 2008; 67:351-7.

5. Phelan J, Link B, Dovidio J. Stigma and prejudice: one animal or two? Soc Sci Med 2008; 67:358-67.

6. Herek G, Capitanio J. AIDS stigma and sexual prejudice. Am Behav Sci 1999; 42:1130-47.

7. Link B. Understanding labeling effects in the area of mental disorders: an assessment of the effects of expectations of rejection. Am Sociol Rev 1987; 52:96-112.

8. Yang L, Kleinman A. 'Face' and the embodiment of stigma: schizophrenia and AIDS in China. Soc Sci Med 2008; 67:398-408.

9. Phelan J, Link B, Moore R, Steuve A. The stigma of homelessness: the impact of the label 'homeless' on attitudes toward a poor person. Soc Psychol Q 1997; 60:323-37.

10. Blank RM, Dabady M, Citro CF, editors. Measuring racial discrimination. Panel on methods for assessing discrimination. Washington DC: National Research Council, National Academies Press; 2004.

11. Williams DR, Williams-Morris R. Racism and mental health: the African American experience. Ethn Health 2000; 5:243-68.

12. Clark R, Anderson NB, Clark VR, Williams DR. Racism as a stressor for African Americans: a biopsychosocial model. Am Psychol 1999; 54:805-16.

13. Williams DR, Gonzalez HM, Williams S, Mohammed SA, Moomal H, Stein DJ. Perceived discrimination, race and health in South Africa. Soc Sci Med 2008; 67:441-52.

14. Meyer IH. Prejudice as stress: conceptual and measurement problems. Am J Public Health 2003; 93:262-6.

15. Huebner DM, Rebchook GM, Kegeles SM. Experiences of harassment, discrimination, and physical violence among young gay and bisexual men. Am J Public Health 2004; 94:1200-3.
16. García-Moreno C, Heise L, Jansen HAFM, Ellsberg M, Watts C. Violence against women. Science 2005; 25:1282-3.

17. Krug EG, Dahlberg LL, Mercy JA, Zwi AB, Lozano R, editors. World report on violence and health. Geneva: World Health Organization; 2002.

18. Parker R, Aggleton P. HIV and AIDS-related stigma and discrimination: a conceptual framework and implications for action. Soc Sci Med 2003; 57: 13-24.

19. Maluwa M, Aggleton P, Parker R. HIV and AIDSrelated stigma, discrimination, and human rights. Health Hum Rights 2002; 6:1-18.

20. Galtung J. Violence, peace, and peace research. J Peace Res 1969; 6:167-91.

21. Galtung J. Kulturelle Gewalt. Der Burger im Staat 1993; 43:106-12.

22. Farmer P. An anthropology of structural violence. Curr Anthropol 2004; 45:305-17.

23. Farmer P. Pathologies of power: health, human rights, and the new war on the poor. Berkeley/Los Angeles/London: University of California Press; 2005.

24. Parker R. The global HIV/AIDS pandemic, structural inequalities, and the politics of international health. Am J Public Health 2002; 93:343-6.

25. Link B, Phelan J. Social conditions as fundamental causes of disease. J Health Soc Behav 1995; Spec No:80-94.

26. Parker R. Grassroots activism, civil society mobilization, and the politics of the global HIV/AIDS epidemic. Brown Journal of World Affairs; in press.

27. Birn AE. Making it politic(al): closing the gap in a generation: health equity through action on the social determinants of health. Social Medicine 2009; 4:166-82.

28. Hunt P. Missed opportunities: human rights and the Commission on Social Determinants of Health. Glob Health Promot 2009; 16:36-41.

Submitted on $11 / \mathrm{Jul} / 2011$

Approved on 04/Aug/2011 